\title{
Results from a Phase IIA Parallel Group Study of JNJ-40346527, an Oral CSF-1R Inhibitor, in Patients with Active Rheumatoid Arthritis despite Disease-modifying Antirheumatic Drug Therapy
}

\author{
Mark C. Genovese, Elizabeth Hsia, Stanley M. Belkowski, Caly Chien, Tara Masterson, \\ Robin L. Thurmond, Carl L. Manthey, Xiaoyu (David) Yan, Tingting Ge, Carol Franks, \\ and Andrew Greenspan
}

ABSTRACT. Objective. To assess the efficacy and safety of JNJ-40346527, a selective inhibitor of colony-stimulating factor-1 (CSF-1) receptor kinase that acts to inhibit macrophage survival, proliferation, and differentiation in patients with active rheumatoid arthritis (RA) despite disease-modifying antirheumatic drug (DMARD) therapy.

Methods. In this randomized, double-blind, placebo-controlled, parallel group study, adults were randomized (2:1) to receive oral JNJ-40346527 $100 \mathrm{mg}$ or placebo twice daily through Week 12 . Patients with RA had disease activity $[\geq 6$ swollen/ $\geq 6$ tender joints, C-reactive protein $(\mathrm{CRP}) \geq 0.8$ $\mathrm{mg} / \mathrm{dl}$ ] despite DMARD therapy for $\geq 6$ months. The primary endpoint was change from baseline at Week 12 in the 28-joint Disease Activity Score with CRP (DAS28-CRP). Pharmacokinetic/pharmacodynamic analyses were also performed, and safety was assessed through Week 16.

Results. Ninety-five patients were treated (63 JNJ-40346527, 32 placebo); 8 patients discontinued treatment (6 JNJ-40346527, 2 placebo) through Week 12. Mean improvements in DAS28-CRP from baseline to Week 12 were 1.15 for the JNJ-40346527 group and 1.42 for the placebo group $(\mathrm{p}=0.30)$; thus, a statistically significant difference was not observed for the primary endpoint. Pharmacokinetic exposure to JNJ-40346527 and its active metabolites was above the projected concentration needed for pharmacologic activity, and effective target engagement and proof of activity were demonstrated by increased levels of CSF-1 and decreased CD16+ monocytes in JNJ-40346527-treated, but not placebo-treated, patients. Thirty-seven (58.7\%) JNJ-40346527-treated and 16 (50.0\%) placebo-treated patients reported $\geq 1$ adverse event (AE); 1 (1.6\%) JNJ-40346527-treated and 3 (9.4\%) placebo-treated patients reported $\geq 1$ serious AE.

Conclusion. Although adequate exposure and effective peripheral target engagement were evident, JNJ-40346527 efficacy was not observed in patients with DMARD-refractory active RA. ClinicalTrials.gov identifier: NCT01597739. EudraCT Number: 2011-004529-28. (First Release August 1 2015; J Rheumatol 2015;42:1752-60; doi:10.3899/jrheum.141580)

Key Indexing Terms:

RHEUMATOID ARTHRITIS COLONY-STIMULATING FACTOR-1 EFFICACY SAFETY

Rheumatoid arthritis (RA) is a systemic, chronic autoimmune disease that, if not adequately treated, leads to progressive joint destruction with consequent disability, loss of function, work incapacity, decreased quality of life, and decreased life expectancy ${ }^{1}$. Patients with an inadequate response to treatment with traditional disease-modifying antirheumatic drugs (DMARD) such as methotrexate (MTX) may be treated with biologic DMARD [e.g., tumor necrosis factor
From the Division of Rheumatology, Stanford University, Palo Alto; Immunology, and Biostatistics, Janssen Research and Development LLC, La Jolla, California; Immunology, Janssen Research and Development, LLC, Spring House; Medical Affairs, Janssen Scientific Affairs LLC, Horsham, Pennsylvania; Quantitative Sciences, Janssen Research and Development LLC, Titusville, New Jersey, USA.

Supported by Janssen Research and Development LLC. Mark Genovese has received consulting fees and research support from Janssen. Elizabeth Hsia, Stanley M. Belkowski, Caly Chien, Tara Masterson, Rob Thurmond, Carl Manthey, Xiaoyu (David) Yan, Tingting Ge, Carol Franks, and Andrew Greenspan are employed by Janssen.

M.C. Genovese, MD, Division of Rheumatology, Stanford University; E. Hsia, MD; S.M. Belkowski, PhD, Immunology, Janssen Research and

\begin{abstract}
Development LLC; C. Chien, PhD, Quantitative Sciences, Janssen Research and Development LLC; T. Masterson, MS; R.L. Thurmond, PhD; C.L. Manthey, PhD, Immunology, Janssen Research and Development LLC; X. Yan, PhD, Quantitative Sciences, Janssen Research and Development LLC; T. Ge, PhD, Biostatistics, Janssen Research and Development LLC; C. Franks, BS, Immunology, Janssen Research and Development LLC; A. Greenspan, MD, Medical Affairs, Janssen Scientific Affairs $L L C$.

Address correspondence to Dr. A. Greenspan, Vice President Medical Affairs, Janssen Scientific Affairs LLC, 800 Ridgeview Drive, Horsham, Pennsylvania 19044,USA. E-mail: AGreensp@its.jnj.com

Full Release Article. For details see Reprints/Permissions at jrheum.org Accepted for publication June 11, 2015.
\end{abstract}


(TNF) inhibitors, abatacept, rituximab, tocilizumab] or newer generation kinase inhibitors (e.g., tofacitinib), which have demonstrated significant efficacy in controlling joint damage and improving physical function and quality of life $e^{2,3,4}$. Despite this, substantial proportions of patients discontinue biologic treatment because of inadequate efficacy or adverse events (AE) ${ }^{5}$. Thus, new therapeutic strategies with different mechanisms of action in RA are needed.

Evidence supports the role of colony-stimulating factors (CSF) in the pathogenesis of RA ${ }^{6}$. In particular, the CSF-1 receptor (CSF-1R), which modulates monocyte differentiation, survival, and proliferation and osteoclast and dendritic cell differentiation, has been implicated in RA pathogenesis. CSF-1R expression in humans has been shown to be increased in the synovium of patients with RA compared with patients with osteoarthritis and healthy controls ${ }^{7}$. CSF-1R is a receptor tyrosine kinase, and CSF-1R kinase inhibition in a rodent model of collagen-induced arthritis has been shown to halt cartilage damage, bone erosion, and systemic bone loss ${ }^{7}$.

Based on the current understanding of their mechanisms of action, JNJ-40346527, a selective CSF-1R kinase inhibitor, and traditional DMARD may have complementary effects in reducing RA inflammation. Thus, our phase II study was conducted after completion of a phase I study that showed excellent inhibition of CSF-1 along with no treatment-limiting toxicities, to assess the safety, tolerability, and efficacy of JNJ-40346527 administered for 12 weeks to patients with active RA despite DMARD therapy.

\section{MATERIALS AND METHODS}

Ethics. Our study (NCT01597739; EudraCT Number: 2011-004529-28) was conducted according to the principles of the Declaration of Helsinki and Good Clinical Practices. The study protocol was approved by the ethical bodies at each participating site, and all patients provided written informed consent prior to the conduct of any study-specific procedures.

Patients. Eligible adults (aged 18-80 yrs) included those with RA according to the revised 1987 American Rheumatism Association criteria ${ }^{8}$ for $\geq 6$ months, and who had active disease despite MTX, sulfasalazine (SSZ), and/or hydroxychloroquine (HCQ) therapy at the time of screening. Active RA was defined as persistent disease activity with $\geq 6$ swollen and $\geq 6$ tender joints at screening and baseline, and a screening C-reactive protein (CRP) level $\geq 0.8 \mathrm{mg} / \mathrm{dl}$ [upper limit of normal (ULN) $1.0 \mathrm{mg} / \mathrm{dl}$ ]. Patients had to have been treated with MTX, SSZ, HCQ, or any combination thereof for $\geq$ 6 months prior to screening, with a stable dose for $\geq 8$ weeks prior to screening. Previous receipt of an approved or investigational biologic antirheumatic agent excluded patient participation. Eligible patients also had to demonstrate serum positivity for either anticyclic citrullinated peptide antibody or rheumatoid factor. In addition, patients were required to meet criteria for concomitant medications, screening clinical laboratory testing, and tuberculosis history/screening results.

Study design. In this randomized, double-blind, placebo-controlled, parallel group study, about 90 patients with RA despite DMARD therapy were randomly assigned in a 2:1 ratio to receive JNJ-40346527 $100 \mathrm{mg}$ twice daily $(200 \mathrm{mg} /$ day) or placebo twice daily, respectively. The sponsor-generated randomization scheme was stratified by baseline MTX usage (yes/no) and country/study site. Patients received study treatment for 12 weeks while also continuing to receive stable DMARD therapy (MTX, SSZ, HCQ, or any combination thereof). Patients were followed through Week 16.
Study evaluations. Efficacy assessments included joint assessments (swollen/tender joint counts), patient's global assessment of disease activity, physician's global assessment of disease activity, Health Assessment Questionnaire Disability Index ${ }^{9}$, patient's assessment of pain, serum CRP, and erythrocyte sedimentation rate. Safety assessments included documentation of $\mathrm{AE}$ and clinical laboratory findings.

Blood samples were collected from all patients for pharmacokinetic analysis prior to the next administration of study agent at weeks 1, 2, 4, 6, 8 , and 12 , and 4 weeks after the last dose. An intensive pharmacokinetic substudy was conducted with 25 patients at Week 8. Plasma samples were collected prior to and at 1, 2, 3, and $4 \mathrm{~h}$ following the Week 8 dose. All pharmacokinetic samples were analyzed to determine concentrations of JNJ-40346527 and its active metabolites M2 and M7 (Supplementary Figure 1 , available online at jrheum.org). The pharmacokinetic variables determined included minimum and maximum plasma concentrations and time to maximum concentration at steady state $\left(\mathrm{C}_{\min }, \mathrm{C}_{\max }\right.$, and $\mathrm{T}_{\max }$, respectively). Blood samples were also collected for measurement of variables related to the JNJ-40346527 mechanism of action, e.g., endogenous CSF levels in the blood and circulating CD16+ monocyte counts (Supplementary data for methodological details available online at jrheum.org).

Specific to the use of serum CSF-1 levels to measure target engagement, undiluted sera were analyzed in duplicate using a Human M-CSF Quantikine ELISA Kit (DMC00B, R\&D Systems) according to the manufacturer's instructions. Duplicate values were averaged, and group averages were computed at each timepoint (Supplementary data available online at jrheum.org).

Statistical methodology. Efficacy analyses were conducted for the modified intent-to-treat population, defined as all randomized patients who received $\geq 1$ study agent administration and had baseline and $\geq 1$ postbaseline data points. Missing postbaseline noncomposite endpoint data or missing components of composite endpoints were to be imputed using a last observation carried forward approach. All hypothesis testing was 2-sided $(\alpha=0.05)$.

The primary endpoint was mean change from baseline to Week 12 in 28-joint Disease Activity Score incorporating CRP (DAS28-CRP), and the major secondary endpoints were $\geq 20 \%$ improvement in the American College of Rheumatology response criteria (ACR20) ${ }^{10}$ and DAS28-CRP response (good/moderate response) ${ }^{11,12}$, both at Week 12 . Treatment group differences in efficacy endpoints were assessed using an ANCOVA model with treatment as a fixed factor and baseline DAS28-CRP as a covariate for continuous variables, while those related to dichotomous endpoints, including ACR20 and DAS28-CRP response rates, were assessed using Fisher's exact test.

Pharmacokinetic data were evaluated in patients without missing or deviated pharmacokinetic data that would not have allowed accurate pharmacokinetic assessments. Pharmacokinetic variables at Week 8 were summarized using descriptive statistics. Changes in the concentration of individual biomarkers from baseline to the selected posttreatment timepoints were also to be summarized using descriptive statistics. Regression analysis was performed of CSF-1 levels and the sum of plasma JNJ-40346527 and metabolites concentrations using locally weighted scatterplot smoothing. Increased CSF-1 levels were to provide evidence that the compound was hitting its target, CSF-1R, resulting in reduced clearance of circulating CSF-1 ligand. All patients who received $\geq 1$ dose of the study drug were included in the safety analysis set. AE were summarized using the Medical Dictionary for Regulatory Activities, version 15.0, system organ class/preferred term.

Assuming a mean (SD) treatment difference of 0.8 (1.25) for the primary endpoint, i.e., change in DAS28-CRP from baseline to Week 12, a sample size of 90 patients (30 and 60 in the placebo and JNJ-40346527 groups, respectively) was estimated to provide about $80 \%$ power to detect the difference between the 2 treatment groups ( 2 -sided Student $t$ test, $\alpha=0.05$ ).

\section{RESULTS}

JNJ-40346527. JNJ-40346527, 4-cyano-N-[2-(4,4-dimethylcyclohex-1-en-1-yl) -6-(2,2,6,6-tetramethyl-tetrahydro-2H-py-

Personal non-commercial use only. The Journal of Rheumatology Copyright @ 2015 . All rights reserved. 


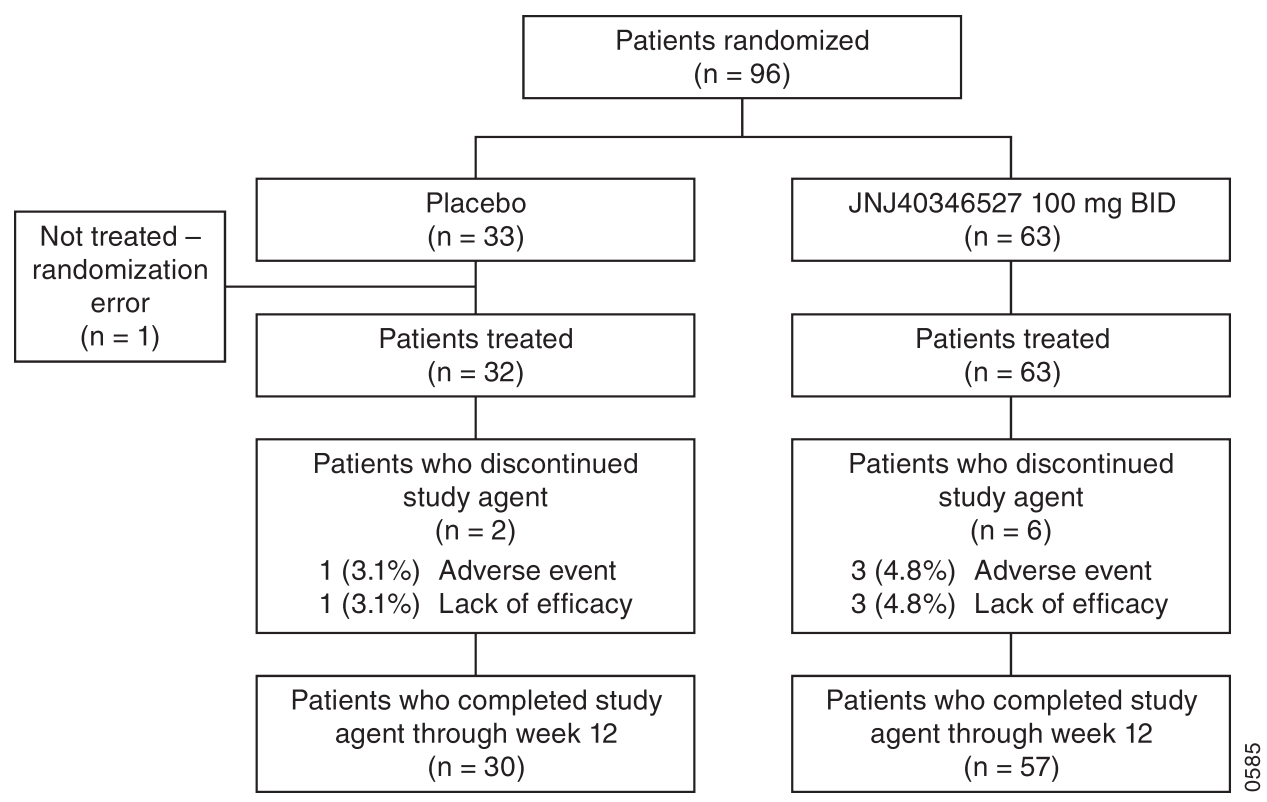

Figure 1. Patient disposition through Week 12.

ran-4-yl)pyridin-3-yl]-1H-imidazole-2-carboxamide ${ }^{13}$, is an investigational agent that selectively inhibits the CSF-1R kinase [concentration required to produce $50 \%$ inhibition $\left.\left(\mathrm{IC}_{50}\right)=3.2 \mathrm{nM}\right]$ and inhibits monocyte/macrophage responses to CSF-1 at concentrations $<10 \mathrm{nM}$ (Supplementary Tables 1-3 available online at jrheum.org). Based on phase I testing, in which no dose-limiting toxicities were observed, and results of a model-based approach used to

Table 1. Summary of baseline demographic and disease characteristics. Values are mean \pm SD or $\mathrm{n}(\%)$ unless otherwise specified.

\begin{tabular}{lccc}
\hline Characteristics & Placebo & $\begin{array}{c}\text { JNJ-40346527 100 mg } \\
\text { Twice Daily }\end{array}$ & All Patients \\
& & 63 & \\
\hline Patients randomized, $\mathrm{n}$ & 33 & $54.2 \pm 11.1$ & $54.3 \pm 10.8$ \\
Age, yrs & $54.7 \pm 10.6$ & $55(87.3)$ & $84(87.5)$ \\
Female & $29(87.9)$ & & \\
Race & & $56(88.9)$ & $86(89.6)$ \\
$\quad$ White & $30(90.9)$ & $7(11.1)$ & $10(10.4)$ \\
Asian & $3(9.1)$ & $7.7 \pm 5.5$ & $7.3 \pm 5.0$ \\
Disease duration, yrs & $6.6 \pm 4.1$ & $24.6 \pm 22.0$ & $24.0 \pm 21.5$ \\
TJC, 0-68 & $22.9 \pm 21.0$ & $14.8 \pm 14.0$ & $14.8 \pm 13.0$ \\
SJC, 0-66 & $14.7 \pm 12.0$ & $6.0 \pm 0.8$ & $5.9 \pm 0.8$ \\
DAS28-CRP & $5.9 \pm 0.9$ & $1.7 \pm 1.8$ & $1.7 \pm 1.8$ \\
HAQ-DI, 0-3 & $1.7 \pm 1.8$ & $2.2 \pm 1.6$ & $2.2 \pm 1.5$ \\
CRP, mg/dl & $2.3 \pm 1.3$ & & \\
Use at baseline & & $59(93.7)$ & $88(91.7)$ \\
Methotrexate & $29(87.9)$ & $16.1 \pm 4.9$ & $15.6 \pm 5.1$ \\
$\quad$ Dose, mg/wk & $14.5 \pm 5.3$ & $9(13.8)$ & $11(11.5)$ \\
Hydroxychloroquine & $2(6.0)$ & $283.3 \pm 93.5$ & $295.5 \pm 90.7$ \\
$\quad$ Dose, mg/day & $350.0 \pm 70.7$ & $9(13.8)$ & $15(15.6)$ \\
Sulfasalazine & $6(18.2)$ & $1500.0 \pm 559.0$ & $1666.7 \pm 617.2$ \\
$\quad$ Dose, mg/day & $1916.7 \pm 664.6$ & $2(3.2)$ & $3(3.1)$ \\
Combination DMARD use* & $1(3.0)$ & $6.2 \pm 2.6$ & $56(58.3)$ \\
Prednisone & $17(51.5)$ & & $6.3 \pm 2.6$ \\
$\quad$ Dose, mg/day & $6.5 \pm 2.6$ & &
\end{tabular}

* Patients received hydroxychloroquine (200-400 mg/day) plus sulfasalazine (1000-1500 mg/day). TJC: tender joint count; SJC: swollen joint count; DAS28: 28-joint Disease Activity Score; CRP: C-reactive protein; HAQ-DI: Health Assessment Questionnaire-Disability Index; DMARD: disease-modifying antirheumatic drug. 
Table 2. Summary of efficacy and safety. Values are $\mathrm{n}$ or $\mathrm{n}(\%)$ unless otherwise specified.

\begin{tabular}{|c|c|c|c|}
\hline Variables & Placebo & $\begin{array}{c}\text { JNJ-40346527 } 100 \mathrm{mg} \\
\text { Twice Daily }\end{array}$ & $\mathrm{p}$ \\
\hline \multicolumn{4}{|c|}{ Efficacy endpoints among patients in the mITT population* } \\
\hline \multicolumn{4}{|c|}{ Improvement from baseline in DAS28-CRP } \\
\hline at Week 12 , primary endpoint & 31 & 61 & \\
\hline Mean $(\mathrm{SD})$ & $1.42(1.187)$ & $1.15(1.186)$ & $0.30 * *$ \\
\hline Median (IQR) & $1.32(0.50-2.29)$ & $0.99(0.38-1.76)$ & \\
\hline \multicolumn{4}{|l|}{ Major secondary endpoints } \\
\hline ACR20 response at Week 12 & $13 / 31(41.9 \%)$ & $30 / 61(49.2 \%)$ & $0.66^{* * *}$ \\
\hline DAS28-CRP response at Week 12 & $20 / 31(64.5 \%)$ & $34 / 61(55.7 \%)$ & $0.50 * * *$ \\
\hline \multicolumn{4}{|l|}{ Additional efficacy endpoints } \\
\hline & \multicolumn{2}{|c|}{ Proportion of patients with HAQ-DI } & $0.51 * * *$ \\
\hline HAQ-DI improvement at Week 12 & 32 & 63 & \\
\hline Mean (SD) & $0.27(0.466)$ & $0.39(0.579)$ & \\
\hline Median (IQR) & $0.25(-0.13-0.56)$ & $0.38(0.13-0.63)$ & $0.21^{\dagger}$ \\
\hline CRP \% improvement at Week 12 & 32 & 63 & $0.35^{\dagger}$ \\
\hline Mean (SD) & $-60.22(339.171)$ & $-19.67(117.571)$ & \\
\hline Median (IQR) & $23.07(-20.71-72.68)$ & $22.87(-63.48-58.35)$ & \\
\hline \multicolumn{4}{|l|}{ Summary of AE among treated patients } \\
\hline Patients treated, $\mathrm{n}$ & 32 & 63 & \\
\hline Patients with $\mathrm{AE}^{\ddagger}$ & $16(50.0)$ & $37(58.7)$ & - \\
\hline \multicolumn{4}{|l|}{ Common $\mathrm{AE},>5 \%$ of patients } \\
\hline Blood lactate dehydrogenase increase & $1(3.1)$ & $9(14.3)$ & \\
\hline Abdominal pain upper & $3(9.4)$ & $1(1.6)$ & \\
\hline Urinary tract infection & $2(6.3)$ & $1(1.6)$ & \\
\hline Patients with serious $\mathrm{AE}^{\ddagger}$ & $3(9.4)$ & $1(1.6)$ & - \\
\hline \multicolumn{4}{|l|}{ Serious AE } \\
\hline Gastroesophageal reflux disease & 0 & $1(1.6)$ & \\
\hline Femur fracture & $1(3.1)$ & 0 & \\
\hline Myositis & $1(3.1)$ & 0 & \\
\hline Calculus ureteric & $1(3.1)$ & 0 & \\
\hline Thrombophlebitis & $1(3.1)$ & 0 & \\
\hline
\end{tabular}

* All randomized patients who had received $\geq 1$ study agent administration and who had baseline and $\geq 1$ postbaseline values. ** $\mathrm{P}$ value derived using ANCOVA model with treatment as a fixed factor and baseline DAS28-CRP as a covariate. *** P values derived using Fisher's exact test. ${ }^{\dagger} \mathrm{P}$ values derived using rank ANCOVA with treatment as fixed effect and baseline score as a covariate. ${ }^{\ddagger}$ Percentages calculated with the number of patients in each treatment group as denominator, $\mathrm{n}$ is the number of patients experiencing $\geq 1 \mathrm{AE}$, not the number of events, and AE were coded using Medical Dictionary for Regulatory Activities 15.0. mITT: modified intent-to-treat; DAS28: 28-joint Disease Activity Score; CRP: C-reactive protein; IQR: interquartile range; ACR20: $\geq 20 \%$ improvement in the American College of Rheumatology response criteria; HAQ-DI: Health Assessment Questionnaire-Disability Index; AE: adverse events.

Table 3. Summary of plasma JNJ-40346527 and metabolite pharmacokinetic variables at Week 8.

\begin{tabular}{|c|c|c|c|c|c|c|c|c|}
\hline \multirow[t]{2}{*}{ Variables } & \multicolumn{3}{|c|}{ Parent, JNJ-40346527 } & \multirow{2}{*}{$\begin{array}{c}\mathrm{M} 7 \\
\mathrm{C}_{\min }, \mathrm{ng} / \mathrm{ml}\end{array}$} & \multirow{2}{*}{$\begin{array}{c}\mathrm{M} 2 \\
\mathrm{C}_{\min }, \mathrm{ng} / \mathrm{ml}\end{array}$} & \multirow{2}{*}{$\begin{array}{c}\mathrm{M} 7: \mathrm{P} \\
\mathrm{C}_{\min } \text { Ratio }\end{array}$} & \multirow{2}{*}{$\begin{array}{c}\mathrm{M} 2: \mathrm{P} \\
\mathrm{C}_{\min } \text { Ratio }\end{array}$} & \multirow{2}{*}{$\begin{array}{l}\mathrm{P}+\mathrm{M} 7+\mathrm{M} 2 \\
\mathrm{C}_{\min }{ }^{* *}, \mathrm{ng} / \mathrm{ml}\end{array}$} \\
\hline & $\mathrm{C}_{\max }, \mathrm{ng} / \mathrm{ml}$ & $\mathrm{T}_{\max } *, \mathrm{~h}$ & $\mathrm{C}_{\min }, \mathrm{ng} / \mathrm{ml}$ & & & & & \\
\hline $\mathrm{n}$ & 25 & 25 & 25 & 25 & 25 & $24^{\dagger}$ & $24^{\dagger}$ & 25 \\
\hline SD & 109 & $(0.0-4.0)$ & 89.1 & 116 & 53.7 & 0.374 & 0.285 & 231 \\
\hline
\end{tabular}

* Median and range reported instead of mean and $\mathrm{SD}$. ** Total $\mathrm{C}_{\min }$ is calculated as the sum of the $\mathrm{C}_{\min }$ concentrations of parent (JNJ-40346527) and its metabolites (M7 and M2). ${ }^{\dagger}$ As the $\mathrm{C}_{\min }$ value for 1 patient was below the limit of quantitation for the denominator, the ratio could not be calculated. P: parent (JNJ-40346527); C: concentration; M: metabolite; $\mathrm{C}_{\max }$ : maximum plasma JNJ-40346527 and metabolite concentration during a dosing interval at steady state; $\mathrm{C}_{\min }$ : minimum plasma JNJ-40346527 concentration during a dosing interval at steady state (may or may not be the trough concentration); $\mathrm{T}_{\max }$ : time to reach the maximum plasma JNJ-40346527 concentration. 
simulate varying exposures, the dose of JNJ-40346527 selected for initial phase II testing was $100 \mathrm{mg}$ twice daily. This dose of JNJ-40346527 was predicted to provide $>90 \%$ inhibition of downstream CSF-1R activity based on the previous phase I testing, thus providing adequate target engagement.

Patient disposition and baseline characteristics. Our study was conducted between May 30, 2012, and April 30, 2013, at 35 sites in 9 countries: Argentina, Bulgaria, Chile, Czech Republic, Hungary, Korea, Poland, Russia, and Ukraine. Among the 96 patients enrolled, 63 and 33 were randomized to receive JNJ-40346527 and placebo, respectively (Figure 1). Because of randomization error (the patient was randomized before knowledge of joint counts, which did not meet the study entrance criteria), 1 placebo patient did not receive the study drug. Among the 95 treated patients, 8 discontinued the study drug through Week 12, including 2 placebo-treated patients (1 patient each because of AE and lack of efficacy) and $6 \mathrm{JNJ}-40346527-$ treated patients (3 patients each because of AE and lack of efficacy). Most enrolled patients were women $(87.5 \%)$ and white $(89.6 \%)$. Demographic characteristics were generally similar between the randomized treatment groups (Table 1).

Efficacy findings. Mean improvements in DAS28-CRP from baseline to Week 12 were 1.15 for the JNJ-40346527 group and 1.42 for the placebo group $(\mathrm{p}=0.30)$. Significant treatment group differences were not observed for either the primary or major secondary efficacy endpoints (Table 2) because of high placebo response rates. Changes in the DAS28-CRP over time are shown in Figure 2. Although the numbers of patients in geographic regions/countries were too small to allow for meaningful formal comparisons, there were no consistent or obvious differences in efficacy by site location (data not shown).

Pharmacokinetic and pharmacodynamic findings. JNJ-40346527 reached steady-state by Week 4 in all patients based on plasma trough levels. Twenty-five patients had plasma samples obtained and evaluable for pharmacokinetic testing at Week 8 (Table 3). Among these patients, the mean maximum JNJ-40346527 concentration $\left(\mathrm{C}_{\max }\right)$ of $347 \mathrm{ng} / \mathrm{ml}$ was observed within $4-\mathrm{h}$ postdose (median time of 2-h postdose). Mean $\mathrm{C}_{\text {min }}$ for JNJ-40346527 and the sum of JNJ-40346527 plus metabolites were $167 \mathrm{ng} / \mathrm{ml}$ and 468 $\mathrm{ng} / \mathrm{ml}$, respectively.

Mean steady-state (average of weeks 4, 6, and 12) CSF-1 levels for each patient directly correlated with the sum of mean (average of weeks 4, 6, and 12) plasma trough levels for JNJ-40346527 and its 2 active metabolites (Supplementary Figure 2, available online at jrheum.org). Effective target engagement and proof of activity was demonstrated by increased levels of CSF-1 (Figure 3A) and decreased CD16+ monocytes (Figure 3B) in JNJ-40346527-treated, but not placebo-treated, patients

Safety findings. Overall, 16 of $32(50.0 \%)$ placebo-treated and 37 of $63(58.7 \%)$ JNJ-40346527-treated patients reported $\geq 1 \mathrm{AE}$. The most common AE included increased blood

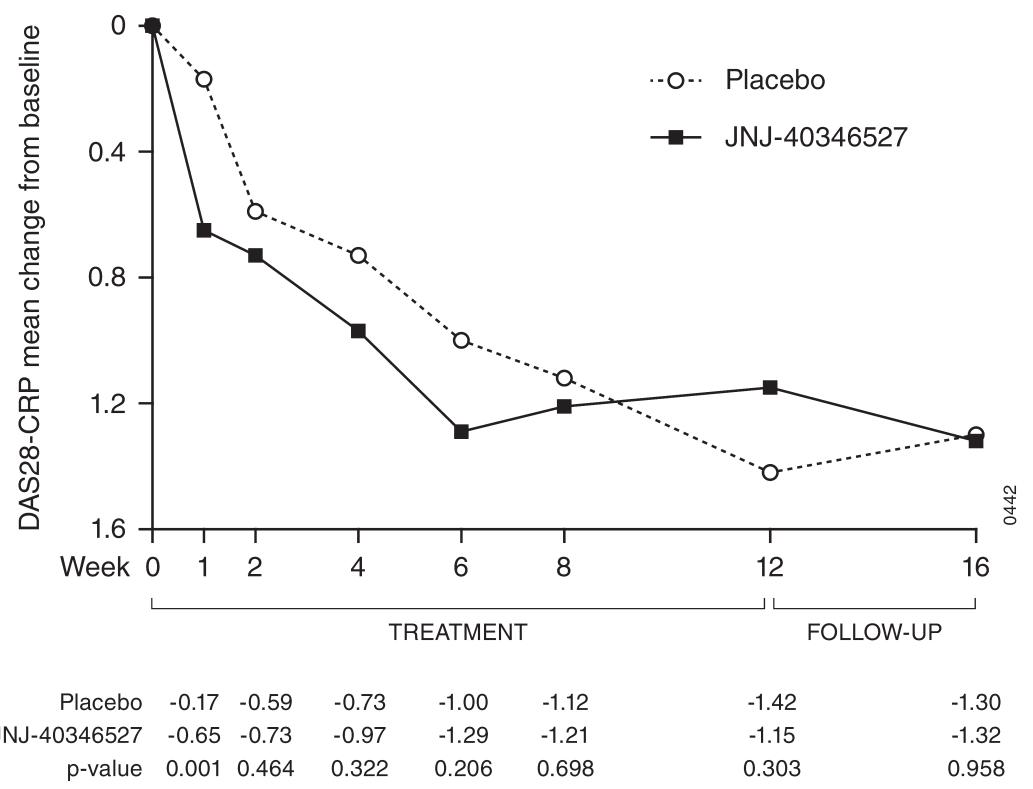

Figure 2. Improvement from baseline in DAS28-CRP score over time, mITT population. $\mathrm{P}$ values derived using an ANCOVA model with treatment as a fixed factor and baseline DAS28-CRP as a covariate; Week $12 \mathrm{p}$ value is the primary analysis, and all other $\mathrm{p}$ values are nominal. DAS28: 28-joint Disease Activity Score; CRP: C-reactive protein; mITT: modified intent-to-treat, defined as all randomized patients who had received $\geq 1$ study agent administration and who had baseline and $\geq 1$ postbaseline values. 

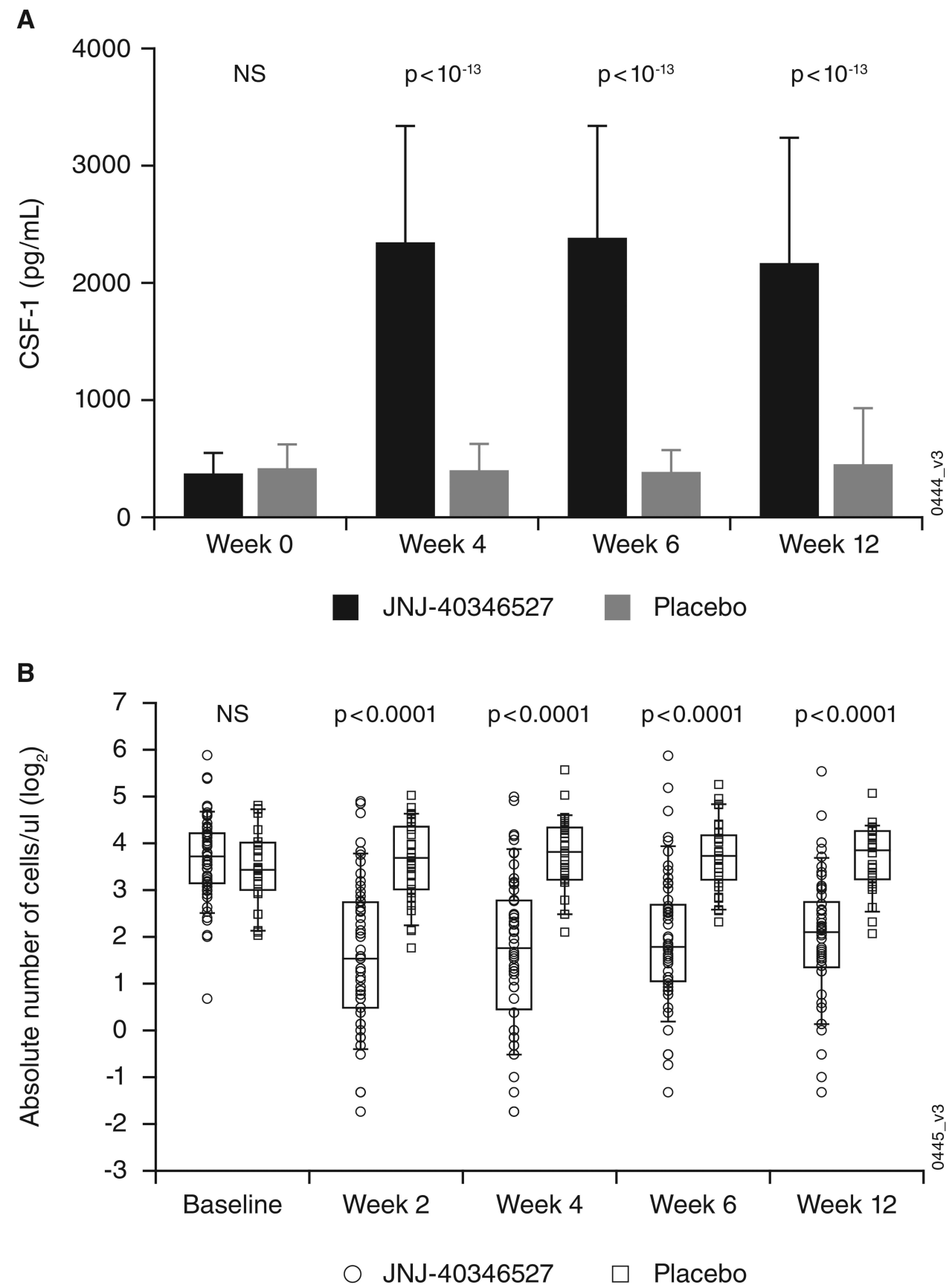

Figure 3. (A) Levels of CSF-1 and (B) CD16+ monocytes over time by treatment group. In Panel B, whiskers represent the 10th and 90th percentiles of levels. CSF-1: colony-stimulating factor-1.

lactate dehydrogenase (LDH) level (3.1\% placebo, $14.3 \%$ JNJ-40346527), upper abdominal pain (9.4\% placebo, $1.6 \%$ JNJ-40346527), and urinary tract infection (6.3\% placebo, $1.6 \%$ JNJ-40346527; Table 2). Four patients discontinued study agent as a result of $\mathrm{AE}$, including 1 (3.1\%) placebo-treated (muscular weakness) and 3 (4.8\%) JNJ-40346527-treated patients (dyspnea, RA, and red blood cell sedimentation rate increased). All events that led to discontinuation were mild in severity. Serious AE were reported by 3 placebo-treated patients $(9.4 \%)$ and 1 JNJ-40346527-treated patient (1.6\%; Table 2). All serious $\mathrm{AE}$ were mild or moderate in intensity. Because periorbital edema has been suggested as a potential side effect of CSF-1 blockade ${ }^{14}$, it is worth noting that periorbital edema was not reported as an $\mathrm{AE}$ in our study.

As expected, based on the mechanism of action (potential 
inhibition of Kupffer cell activity in the liver that serve to clear these enzymes), JNJ-40346527-treated patients experienced mean increases in creatine kinase (138\%), LDH (48\%), aspartate aminotransferase (AST; 33\%), and alanine aminotransferase (ALT; 24\%) compared with minimal changes in placebo-treated patients across all 4 variables.

Four patients receiving JNJ-40346527 experienced ALT elevations to $>3 \times$ the ULN compared with no placebo-treated patient. No patients experienced elevated bilirubin. Mild decreases in neutrophils and total monocytes were observed that also may be related to the mechanism of action, i.e., effects of JNJ-40346527 on CSF-1R antagonism on precursor cells in the bone marrow.

\section{DISCUSSION}

Macrophages are believed to be important in RA pathology, and CSF-1 and its cellular receptor CSF-1R are key macrophage regulators. Therefore, inhibition of CSF-1/CSF-1R by JNJ-40346527, an orally available inhibitor of CSF-1R receptor tyrosine kinase, was selected for study as a potential disease-modifying treatment for RA. The dose of $100 \mathrm{mg}$ twice daily was selected based on modeling that predicted the dose would provide trough levels that would be above the level predicted from animal studies to yield efficacy, be sufficient for $>90 \%$ inhibition of CSF-1R activity, and provide at least a 1-fold margin below the no-adverse-effect levels observed in toxicology studies.

The most common AE among JNJ-40346527-treated patients were related to clinical laboratory evaluations. The mean increases in liver function enzymes, including creatine kinase, LDH, AST, and ALT, observed more commonly in JNJ-40346527-treated than placebo-treated patients, are expected given that the active agent can potentially inhibit Kupffer cell activity in the liver that serves to clear these enzymes ${ }^{15}$. Similar side effects have been observed in healthy subjects receiving a monoclonal antibody directed against CSF-1 (PD-0360324) ${ }^{14}$. Thus, no new or unexpected safety findings emerged during our study, and the observed laboratory abnormalities would not have prevented drug development had efficacy of the study agent been more robust.

In these patients with RA, no clinical evidence of efficacy was observed in the JNJ-40346527 group compared with the placebo group. Target engagement was confirmed in a previous phase I JNJ-40346527 trial, wherein direct measurement of the inhibition of ex vivo CSF-1R phosphorylation by the compound was performed, resulting in a correlation between the reduction of phosphorylation and the increase in drug concentration. In our current multicenter phase II study, however, using such a labor-intensive analysis was not practical. Therefore, we used an indirect measure of CSF-1R inhibition. When the CSF-1R is inhibited, levels of CSF-1 ligand are increased in the periphery because of the lack of internalization by the receptor. The levels of CSF-1 were highly elevated in JNJ-40346527-treated patients while those in placebo-treated patients remained at baseline levels (Figure 3A), indicating that the drug was engaging the receptor, resulting in inhibition of receptor function. These elevated levels of CSF-1 also correlated with the levels of parent compound and metabolites (Supplementary Figure 2, available online at jrheum.org). A second measure of the compound's activity was achieved by measuring proinflammatory monocytes (CD14 ${ }^{\text {dim }}, \mathrm{CD} 16^{\text {bright }}$ ) by flow cytometry. These proinflammatory monocytes are elevated in the periphery of patients with RA compared with normal individuals (normal levels $9.5 \pm 2.2 \%$, RA levels $11.7 \pm$ $5.6 \%)^{16}$ and have been shown to be dependent on CSF- $1^{17}$. Significant lower absolute numbers of proinflammatory monocytes were observed at all postdosing timepoints for JNJ-40346527- versus placebo-treated patients in the current trial provide proof of mechanism for JNJ-40346527 (Figure 3B).

Thus, despite evidence that inhibition of CSF-1R was achieved, no efficacy was observed in the MTX-refractory patients with RA of longstanding duration (mean of $7.3 \mathrm{yrs}$ ), suggesting that the receptor does not play a major role in the disease pathology. One caveat, however, is the high placebo response rate seen in our study. For comparison, in a phase IIB trial of tofacitinib, an orally administered Janus kinase inhibitor, the mean improvement in the DAS28-CRP from baseline to Week 12 in the placebo group (0.84) was lower than that observed in our trial (1.15), while the mean improvements were similar for tofacitinib $1 \mathrm{mg}$ twice daily (1.42) and JNJ-40346527 (1.42) ${ }^{18}$. In addition, patients with RA enrolled in more recently conducted MTX-experienced trials have had lower disease activity than in previous eras of patient care ${ }^{19}$, potentially impairing a trial's ability to discern a treatment effect, especially in a smaller proof-of-concept trial of DMARD-experienced patients such as ours.

Numbers of CD68+ macrophages within rheumatoid synovial sublining tissue have demonstrated a positive correlation with clinical symptoms ${ }^{20}$, and macrophages are a source of key mediators [e.g., TNF, interleukin (IL) 6, IL-23]. Collectively, this led to the hypothesis that targeting macrophages may result in successful new therapeutics. Prominent among the several mediators of macrophage lineage development are granulocyte-macrophage (GM)-CSF and CSF-1R ligands, CSF-1, and IL-34. Inhibition of GM-CSFR $\alpha$ and CSF-1R has now been tested for clinical efficacy in RA. In the phase II trial of mavrilimumab (anti-GM-CSFR $\alpha$ ), all doses combined of mavrilimumab $(\mathrm{n}=158)$ were associated with a significantly higher proportion of patients achieving $\mathrm{a} \geq 1$.2-point reduction in DAS28-CRP than placebo $(\mathrm{n}=75)$ at Week $12(55.7 \%$ vs $34.7 \%, \mathrm{p}=0.003)^{21}$. It is tempting to conclude that the efficacy of mavrilimumab may partly validate the targeting of macrophages, although the cellular pharmacology of GM-CSF antagonism may be complex because of the effect

Personal non-commercial use only. The Journal of Rheumatology Copyright $\subset$ 2015 . All rights reserved. 
of this cytokine not only on macrophages but also on neutrophils, eosinophils, and perhaps other cell lineages. Setting these differences aside, distinct roles of GM-CSF and CSF-1R ligands as macrophage growth factors may also help explain the apparent lack of efficacy of JNJ-40346527.

During inflammation, generally and in RA synovium specifically, both GM-CSF and the CSF-1R ligands are increased and preclinical studies indicate that both contribute, albeit through different mechanisms, to the recruitment of exudative macrophages during acute inflammation. Studies in GM-CSF-deficient mice suggested a systemic role (e.g., bone marrow) for GM-CSF in maintaining an available pool of immature monocytes for extravasation ${ }^{22}$, whereas neutralization of CSF-1 was shown to reduce macrophage numbers by a 3-prong mechanism, i.e., by inhibiting the proliferation and maturation of inflammatory monocyte-derived macrophages and also by blocking the resident macrophage proliferative response to inflammation ${ }^{23}$. Further, in vitro studies have highlighted differences in macrophages caused to differentiate under the influence of GM-CSF versus CSF-124. GM-CSF-derived macrophages have been described as M1-like because of a higher capacity for lipopolysaccharide (LPS)-induced IL-23 expression ${ }^{24}$. In contrast, CSF-1-derived macrophages have a higher capacity for LPS-induced IL-10 expression, a characteristic that is consistent with the role of CSF-1 in maintaining resident macrophages. Overall, because resident macrophages may have pro-resolving activity, we speculate that in RA the effect of CSF-1R inhibition on inflammatory macrophages may have been counterbalanced with inhibition of resident-type macrophages, while GM-CSF inhibition may more selectively block the inflammatory macrophage population. While this could explain our results in RA, inhibition of CSF-1R may nonetheless lead to improvement in other inflammatory disorders where macrophages exhibit an aberrant CSF-1 response, as described ${ }^{25}$.

\section{ACKNOWLEDGMENT}

The authors thank the patients, the investigators, and the study personnel who made this trial possible. The authors also thank Michelle Perate, MS, and Mary Whitman, PhD, of Janssen Scientific Affairs LLC, medical writing professionals who helped draft, collate author comments for, collect approvals, and submit the manuscript.

\section{ONLINE SUPPLEMENT}

Supplementary data for this article are available online at jrheum.org.

\section{REFERENCES}

1. McInnes IB, Schett $\mathrm{G}$. The pathogenesis of rheumatoid arthritis. N Engl J Med 2011;365:2205-19.

2. Singh JA, Furst DE, Bharat A, Curtis JR, Kavanaugh AF, Kremer JM, et al. 2012 update of the 2008 American College of Rheumatology recommendations for the use of disease-modifying antirheumatic drugs and biologic agents in the treatment of rheumatoid arthritis. Arthritis Care Res 2012;64:625-39.

3. O'Dell JR, Mikuls TR, Taylor TH, Ahluwalia V, Brophy M, Warren $\mathrm{SR}$, et al. Therapies for active rheumatoid arthritis after methotrexate failure. N Engl J Med 2013;369:307-18.

4. Burmester GR, Blanco R, Charles-Schoeman C, Wollenhaupt J, Zerbini C, Benda B, et al; ORAL Step investigators. Tofacitinib (CP-690,550) in combination with methotrexate in patients with active rheumatoid arthritis with an inadequate response to tumour necrosis factor inhibitors: a randomised phase 3 trial. Lancet 2013;381:451-60.

5. Papagoras C, Voulgari PV, Drosos AA. Strategies after the failure of the first anti-tumor necrosis factor alpha agent in rheumatoid arthritis. Autoimmun Rev 2010;9:574-82.

6. Hamilton JA. Colony-stimulating factors in inflammation and autoimmunity. Nat Rev Immunol 2008;8:533-44.

7. Toh ML, Bonnefoy JY, Accart N, Cochin S, Pohle S, Haegel H, et al. Bone- and cartilage-protective effects of a monoclonal antibody against colony-stimulating factor 1 receptor in experimental arthritis. Arthritis Rheum 2014;66:2989-3000.

8. Arnett FC, Edworthy SM, Bloch DA, McShane DJ, Fries JF, Cooper NS, et al. The American Rheumatism Association 1987 revised criteria for the classification of rheumatoid arthritis. Arthritis Rheum 1988;31:315-24.

9. Fries JF, Spitz P, Kraines RG, Holman HR. Measurement of patient outcome in arthritis. Arthritis Rheum 1980;23:137-45.

10. Felson DT, Anderson JJ, Boers M, Bombardier C, Furst D, Goldsmith C, et al. American College of Rheumatology. Preliminary definition of improvement in rheumatoid arthritis. Arthritis Rheum 1995;38:727-35.

11. Prevoo ML, van 't Hof MA, Kuper HH, van Leeuwen MA, van de Putte LB, van Riel PL. Modified disease activity scores that include twenty-eight-joint counts. Development and validation in a prospective longitudinal study of patients with rheumatoid arthritis. Arthritis Rheum 1995;38:44-8.

12. Wells G, Becker JC, Teng J, Dougados M, Schiff M, Smolen J, et al. Validation of the 28-joint Disease Activity Score (DAS28) and European League Against Rheumatism response criteria based on C-reactive protein against disease progression in patients with rheumatoid arthritis, and comparison with the DAS28 based on erythrocyte sedimentation rate. Ann Rheum Dis 2009;68:954-60.

13. Kolodziejczyk K, Stappers AE, Teleha CA, Weerts KJH. United States patent application US 2014/0045789 A1. Process for the preparation of C-FMS kinase inhibitors. Washington, DC: US Patent Office; 2014

14. Sadis S, Mukherjee A, Olson S, Dokmanovich M, Maher R, Cai $\mathrm{CH}$, et al. Safety, pharmacokinetics, and pharmacodynamics of PD-0360324, a human monoclonal antibody to monocyte/macrophage colony stimulating factor, in healthy volunteers. Arthritis Rheum 2009;60 Suppl 10:408.

15. Radi ZA, Koza-Taylor PH, Bell RR, Obert LA, Runnels HA, Beebe JS, et al. Increased serum enzyme levels associated with sr cell reduction with no signs of hepatic or skeletal muscle injury. Am J Pathol 2011;179:240-7.

16. Kawanaka N, Yamamura M, Aita T, Morita Y, Okamoto A, Kawashima M, et al. CD14+,CD16+ blood monocytes and joint inflammation in rheumatoid arthritis. Arthritis Rheum 2002;46:2578-86.

17. Korkosz M, Bukowska-Strakova K, Sadis S, Grodzicki T, Siedlar M. Monoclonal antibodies against macrophage colony-stimulating factor diminish the number of circulating intermediate and nonclassical (CD14(++)CD16(+)/CD14(+)CD16(++)) monocytes in rheumatoid arthritis patient. Blood 2012;119:5329-30.

18. Kremer JM, Cohen S, Wilkinson BE, Connell CA, French JL, Gomez-Reino J, et al. A phase IIb dose-ranging study of the oral JAK inhibitor tofacitinib (CP-690,550) versus placebo in combination with background methotrexate in patients with active rheumatoid arthritis and an inadequate response to methotrexate alone. Arthritis Rheum 2012;64:970-81.

Personal non-commercial use only. The Journal of Rheumatology Copyright @ $\odot 2015$. All rights reserved 
19. Rahman MU, Buchanan J, Doyle MK, Hsia EC, Gathany T, Parasuraman $\mathrm{S}$, et al. Changes in patient characteristics in anti-tumour necrosis factor clinical trials for rheumatoid arthritis results of an analysis of the literature over the past 16 years. Ann Rheum Dis 2011;70:1631-40.

20. de Hair MJ, Harty LC, Gerlag DM, Pitzalis C, Veale DJ, Tak PP. Synovial tissue analysis for the discovery of diagnostic and prognostic biomarkers in patients with early arthritis. J Rheumatol 2011;38:2068-72.

21. Burmester GR, Weinblatt ME, McInnes IB, Porter D, Barbarash O, Vatutin M, et al. Efficacy and safety of mavrilimumab in subjects with rheumatoid arthritis. Ann Rheum Dis 2013;72:1445-52.

22. Lenzo JC, Turner AL, Cook AD, Vlahos R, Anderson GP, Reynolds EC, et al. Control of macrophage lineage populations by CSF-1 receptor and GM-CSF in homeostasis and inflammation. Immunol Cell Biol 2012;90:429-40.
23. Davies LC, Rosas M, Jenkins SJ, Liao CT, Scurr MJ, Brombacher F, et al. Distinct bone marrow-derived and tissue-resident macrophage lineages proliferate at key stages during inflammation. Nat Commun 2013;4:1886.

24. Lacey DC, Achuthan A, Fleetwood AJ, Dinh H, Roiniotis J, Scholz GM, et al. Defining GM-CSF- and macrophage-CSF-dependent macrophage responses by in vitro models. J Immunol 2012;188:5752-65

25. Iwata Y, Boström EA, Menke J, Rabacal WA, Morel L, Wada T, et al. Aberrant macrophages mediate defective kidney repair that triggers nephritis in lupus-susceptible mice. J Immunol 2012;188:4568-80. 